\title{
Restrictive Transfusion Policy on Anemia - An Ideal Strategy in Critically Ill Patient
}

\author{
Authors
}

\section{Dr Pradipta Kumar Patel ${ }^{1}$, Dr Arata Kumar Swain ${ }^{2}$}

${ }^{1}$ Associate Professor, HOD, Anaesthisiology \& Critical Care, VSS Medical College, Burla ${ }^{2}$ M.D, FCCM, Assistant Professor, Dept of Anaesthisiology \& Critical Care, VSS Medical College, Burla

\section{Abstract}

A total of 100 patients were included for three years in the study from 2012 Mach to 2015 March. This study aims to assess the prevalence of Anemia in critically ill patients and studies the association of blood transfusion and mortality in critically ill patients. It also compares restrictive transfusion policy $(\mathrm{Hb}<7 \mathrm{~g} / \mathrm{dl})$ and liberal transfusion policy $(\mathrm{Hb}<10 \mathrm{~g} / \mathrm{dl})$. Out of the 100 patients studied, 38 patients were given blood transfusion and matching control patients were identified for 36 patients. The mortality in the transfusion group was $58.33 \%$ when compared to $25.0 \%$ in the non transfusion group (P 0.005). The attributable mortality was $33.33 \%$ with a relative rish of 2.33 .

\section{INTRODUCTION}

A hematocrit between $20 \%$ and $25 \%$ was considered an urgent indication for transfusion, but at the turn of this century, maintaining a hematocrit at this level is considered to be "bestpractice medicine". (1)

Anemia is apparently tolerated in most patients, particularly those who are young/relatively healthy, the ICU population must be thought of differently. Anemia in the ICU may be due to acute blood loss, phlebotomy or to the present of inflammatory disease. The risks of blood transfusions are many. Nonetheless, Hemoglobin levels at or above $10 \mathrm{~g} / \mathrm{dl}$ may be important for oxygen delivery to vital organs, especially in critically ill patients with increased oxygen demands. ${ }^{(1)}$ The appropriate transfusion trigger for critically ill patients in this setting remains unknown.

\section{Aim}

This study aims to assess the prevalence of anemia in critically ill patients and studies the association of blood transfusion and mortality in critically ill patients. It also compares restrictive transfusion policy $(\mathrm{Hb}<7 \mathrm{~g} / \mathrm{dl})$ and liberal transfusion policy $(\mathrm{Hb}<10 \mathrm{~g} / \mathrm{dl})$.

\section{MATERIALS AND METHODS}

A total of 100 patients were included for three years in the study from 2012 Mach to 2015 March. A matched cohort study was performed. The complete blood court was done every week and patients were followed for 21 days or till death/transfer from the ICU. The following standards were used for case identification:- $\mathrm{Hb}$ less than $12 \mathrm{~g} / \mathrm{dl}$ (males). Hb less than $10 \mathrm{~g} / \mathrm{dl}$ (females) [any single episode during ICU stay]. 


\section{Inclusion Criteria}

All patients admitted in the intensive care unit during the study period in the age group of 15-65 years.

\section{Exclusion Criteria}

1. HIV positive patients

2. Hematological malignancies

3. Patients with a known hematological disorder

4. Patients on chemotherapy

\section{Matching and selection of control patients}

The study the association between blood transfusion and mortality, control patients were those who never received blood during ICU stay. They were selected according to the following criteria:

- Age $( \pm 5$ years $)$

- Sex

- APACHE 11 score on first day of ICU admission ( \pm 5 points)

- History of cardiac disease (ischemic heart disease, congestive heart failure)

- History of renal disease (acute or chronic renal failure)

- Clinical diagnosis

- The Chi-square test was used for statistical significance and $\mathrm{P}<0.05$ was considered significant at $95 \%$ confidence interval.

\section{RESULT}

The study cohort of 100 patients had an average APACHE score of 16.2. The overall mortality was $46 \%$ and the age-wise distribution of mortality was as shown in Table. 1.

\begin{tabular}{lc}
\hline Table 1: Age wise distribution of mortality \\
\hline Age (years) & Number of deaths \\
$15-24$ & 6 \\
$25-34$ & 8 \\
$35-44$ & 11 \\
$45-54$ & 12 \\
$55-64$ & 9 \\
\hline
\end{tabular}

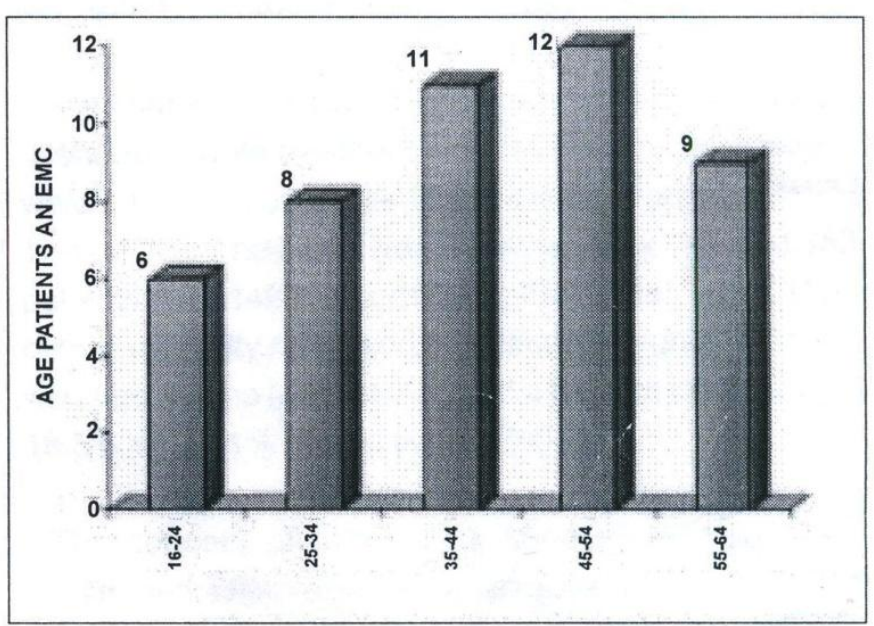

Bar diagram showing age-wise distribution of mortality

1. Out of 100 patients 68 were found to be anemic during the study period. The mean $\mathrm{Hb}$ level was $8.72 \mathrm{~g} / \mathrm{dl}$. The predominant peripheral smear picture was of microcytic hypochromic type. The others were normocytic normochromic with $3 \%$ showing a leukemoid reaction [table 2].

Table 2: The predominant peripheral smear picture was microcytic hypochromic

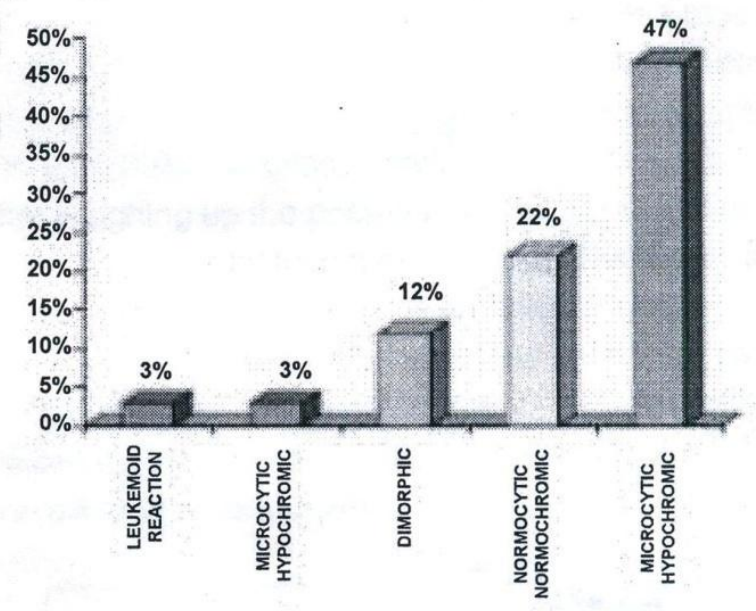

2. Spesis was the commonest clinical setting associated with anemia. The others being gastrointestinal bleed, chronic renal failure and postoperative blood loss [Table 3]. 
Table 3: Causes of anemia identified in the study

\section{Aetiology}

GI. Bleed

CRF

Sepsis

Blood loss due to internal hemorrhage,

post operative etc.

Protozoal infections (malaria, leptospirosis)

No. of patients
8
9
33
9
8

3. Out of the 100 patients studied, 38 patients were given blood transfusion and matching control patients were identified for 36 patients. The mortality in the transfusion group was $58.33 \%$ when compared to $25.0 \%$ in the non transfusion group ( $P$ 0.005). The attributable mortality was $33.33 \%$ with a relative rish of 2.33 [Table 4].

Table 4: Association between blood transfusion and mortality

\begin{tabular}{lcc}
\hline & No. of deaths & No. of survivors \\
Total number transfused & 21 & 15 \\
Number of patients not transfused & 9 & 27 \\
\hline
\end{tabular}

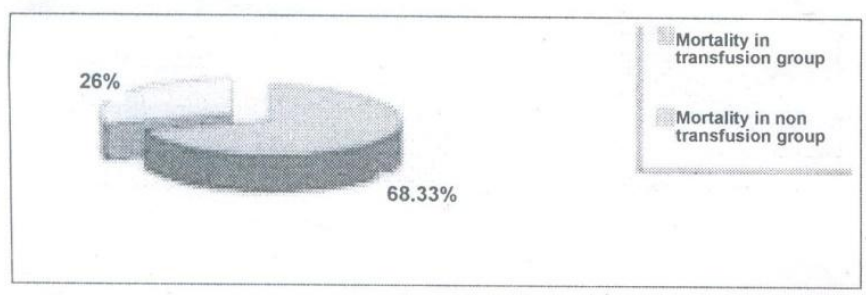

Pie diagram showing mortality in transfused and non transfused groups

4. The mortality rate in those transfused at $\mathrm{Hb}<7 \mathrm{~g} / \mathrm{l}$ was $10 \%$ when compared to $70 \%$ mortality rate in those transfused at $\mathrm{Hb}<10$ $\mathrm{g} / \mathrm{l}$ (P 0.005) [Table 5].

\begin{tabular}{|c|c|c|}
\hline Mortality & $\begin{array}{c}\text { Restrictive transfusion } \\
\text { (Trigger }<7 \mathrm{~g} / \mathrm{L} \text { ) } \\
10.0 \%\end{array}$ & $\begin{array}{c}\text { Liberal transfusion } \\
\text { (Trigger }<10 \mathrm{~g} / \mathrm{L}) \\
70.0 \%(P 0.005)\end{array}$ \\
\hline
\end{tabular}

5. The duration of stay in the ICU was doubled in anemic patients [Table 6].

Table 6: Duration of ICU stay

\begin{tabular}{lcc}
\hline & Anemia & Normal $\mathrm{Hb}$ \\
Average duration of stay in ICU (days) & 8.72 & 4.10 \\
\hline
\end{tabular}

\section{DISCUSSION}

The study shown that nearly two-thirds of patients admitted to an ICU have Hb levels less than 10 g/l. Anemia may be caused by decreased production of RBCs, nutritional deficiencies, inadequate production of $\mathrm{RBCs}$, inadequate endogenous erythropoietin production. renal failure ans diagnostic blood smpling ${ }^{(3,4)}$.

As anemiz progresses in otherwise healthy persons, compensatory mechanisms are recruited and a certain degree of anemia may be tolerated. These mechanisms may not operate efficiently or at all in critically ill patients. Under various preconditions anemia may be associated with increased mortality of the critically ill. The same is true with blood transfusion ${ }^{(5,6)}$.

The complications of blood transfusions include volume overload, febrile reactions and fatal hemolytic reactions which may all contributed to increase mortality. The anemia and blood transfusions study conducted in western European ICUs also show overall mortality rates were significantly higher in patients who had blood transfusion vs ho had not received transfusion ${ }^{(2)}$.

The concept of optimal $\mathrm{Hb}$ concentration has been challenged. Wilkerson and colleagues using a paralyzed, anesthetized, normovolemic anemic primate model, noted that compensatory mechanisms for lo $\mathrm{Hb}$ concentration did not occur until the $\mathrm{Hb}$ concentration fell below $7 \mathrm{~g} / \mathrm{dl}$.

The study by Hebert et. $\mathrm{Al}^{(7)}$ showed that a restrictive transfusion policy $(\mathrm{Hb}<7 \mathrm{~g} / \mathrm{dl})$ has better overall outcomes that when the transfusion trigger was more liberal $(\mathrm{Hb}<10 \mathrm{~g} / \mathrm{dl})$. The decision to transfuse or not must be taken after weighing up the potential consequences of anemia against blood transfusion associated risks. Every single patient's ability to compensate for anemia is different. The question of whether a potential transfusion is capable of affecting the clinical outcome of a given patient is related to the question whether tissue hypoxia is in fact prevailing at a certain $\mathrm{Hb}$ Concentration. 


\section{REFERENCES}

1. Pearl RG, pohlman A. understanding and managing anemia in critically ill patients, Crit Care Nurse Dec 2002; Suppl:1-14

2. Vincent JL, Baron JF, Reinhart $\mathrm{K}$, Gattinoni L, Thijs L, Webb A, et al. Anemia and blood transfusion in critically ill patients. JAMA 2002;288:1499-507.

3. Civetta JM, Taylar RW, Kirby RR. Transfusion therepy. Crit Care 1996; Vol $3^{\text {rd }}$ Edition:639-52.

4. Shoemaker, Ayers Granvik Holbrook, Thompson : Text book of critical care. P. 903-18.

5. Jesse B Hay, Gregory A Schmidt, Laurence DH Wood. Principles of critical care 1992. P. 1807-17.

6. Evans TW, (2001) Hemodynamic and metabolic therapy in critically ill patients, NEJM 345:1368-77.

7. Herbrt PC, Well G, Tweeddale M, Martin C, Marshall J, Pham B, et al. Does transfusion practice affect mortality in critically ill patients? Am J. Respir Crit Care Med 1997;155:1618-23. 